\title{
Farmers Knowledge, Practices and Perceived Health Symptoms Associated with Pesticides used in Thimi, Bhaktapur, Nepal
}

\author{
${ }^{1}$ Ruchita Sainju \\ ${ }^{1}$ Department of Public Health, Nobel College, Pokhara University, Nepal
}

\begin{abstract}
$\underline{\text { ABSTRACT }}$
Background: All over the world, the use of pesticides is considered the most attractive method of controlling pests which involves less labor and characterizes higher output per hectare of land. I aim to study to assess Farmers Knowledge and Practices of Pesticides used and self-reported health systems associated with pesticides used in Thimi, Bhaktapur.

Methodology: A cross-sectional study was conducted among farmers of Thimi, Bhaktapur. 210 farmers were enrolled in the study. Data collection involved a self-prepared questionnaire to farmers and information was collected by face to face interviews. Socio demographics status, unsafe pesticide handling practices of pesticide storage, conditions of personal protective equipment (PPE) was assessed as per the questionnaires.
\end{abstract}

Results: Out of 210 farmers, who participated in the study, $70 \%$ were male and $30 \%$ were female. Majority $87 \%$ of farmers couldn't read and write. Knowledge regarding the personal protective equipment was known to $85 \%$ used mask, $8 \%$ used gloves. Thus, no farmers were found using boots and goggles. Practices of washing hand among farmers were found to be $93 \%$. Majority (92\%) of the farmers neither smoked nor drank or ate anything during spray of pesticides.

Conclusion: There is a low education level, lack of information about pesticide residue, and inadequate personal protection during pesticide use among farmers in Thimi Bhaktapur.

Keywords: Farmers, Knowledge, Practices. Pesticides, Bhaktapur, Nepal

\section{BACKGROUND}

The population growth, combined with the diet demands of a wealthier populace, is expected to double world food demand by 2050[1-2]. Assuming production, regulation and innovation trends of the past several decades continue, global pesticide production will be 2.7 times higher in 2050 than in 2000, exposing humans and the environment to considerably higher levels of pesticides. . [1].

\footnotetext{
*Correspondance: Ruchita Sainju

${ }^{1}$ Department of Public Health, Nobel College,

Sinamangal, Kathmandu, Nepal, GPO 10420
}

All over the world, the use of pesticides is considered the most attractive method of controlling pests which involves less labor and characterizes higher output per hectare of land. The extensive use of such pesticides results in substantial health and environmental threats. An estimated 1 to 5 million pesticide poisoning incidents occur worldwide each year, mostly in developing countries (FAO, 2004).

Pesticides are important public health tools that are used to prevent vector-borne disease and to increase food supplies. Studies have demonstrated acutely toxic effects at high doses, as well as chronic effects at low levels of 
exposure [2]. Potential acute health effects of pesticide exposure include skin irritation, eye irritation, and shortness of breath, salivation, nausea, vomiting, abdominal cramps, excessive fatigue, headache, muscle twitching, and numbness. Extreme cases of acute pesticide exposure or pesticide poisoning can result in death. An estimated 1 to 5 million pesticide poisoning incidents occur worldwide each year, mostly in developing countries (FAO, 2004). Health outcomes such as attention deficit/hyperactive disorder (ADHD) and Parkinson's disease have also been linked to exposure to certain classes of pesticides [3].

IPM is the selection and use of pest control actions that will ensure favorable economic, ecological and social consequences and is applicable to most agricultural, public health and amenity pest management situations [3]. Reliance on knowledge, experience, observation and integration of multiple techniques makes IPM appropriate for organic farming (excluding synthetic pesticides) [4-6].

\section{METHODOLOGY}

Cross sectional research conducted among farmers in Thimi, Bhaktapur well known pocket area for vegetable production and distribution in Kathmandu valley. The study duration was August-December, 2014. Out of 17 wards, 3 wards were selected by non-probability purposive method on the basis of the highest frequency of the farmers and the respondents were by selected by convenient sampling method. Sample size was calculated by using formula $(\mathrm{n})=4 \mathrm{pq} / \mathrm{d} 2$ [Where $\mathrm{p}=$ prevalence, $\mathrm{q}=$ $100-p, d=$ error (10\% relevant error), prevalence $(p)=50 \%$ (assuming)] Hence, 210 sample size was obtained.

The farmers using pesticides for agricultural growth were only included. The data collection technique is face to face interview. A self-administrated questionnaire .The first section was designed to assess socio demographic status which contained questions regarding age, gender, education level, and years of experience as a farm worker and the Second section was designed to assess participants' pesticide knowledge. Participants were presented with four questions that could be answered by either 'yes', 'no', or 'I do not know'.

One point was given for each correct answer, one point was deducted for each wrong answer, and selecting 'I do not know' did not affect the grade. The range of the knowledge score was -4 to 41 and was categorized as: $<2=$ poor knowledge; and $\geq 2=$ good knowledge.

\section{RESULTS}

The mean age \pm SD of the respondents is $39.5 \pm 7.9$ years. The majority (70\%) of the participants were male. Results related to the educational levels of the participants showed that $186(87 \%)$ had no education and 24 (13\%) could read and write. In this study, $136(65 \%)$ belong to nuclear family, 63(30\%) farmers belong to joint family and $11(5 \%)$ belong to extended family. In this study, 189 farm workers (90\%) stated farming as a primary source of earning whereas for 21 farm workers (21\%) farming is a secondary source of earning. Similarly, 89 farm workers (42\%) stated their monthly income Rs. 5000-10000 and $121(58 \%)$ farm workers have monthly income Rs. $>10000$. The above figure shows $90 \%$ of farmers have knowledge about the health effects due to pesticides use, majority (95\%) farmers have knowledge about use of PPE, $94 \%$ farmers have knowledge regarding entry of pesticides through nose and half of the respondents (50\%) have knowledge about pesticides residue.

The above table shows that most farmers 198 (941\%) don't read and follow label instruction before pesticide application. Similarly, few farmers 15 (7\%) eat/drink during pesticide application, 16(8\%) farmers smoke during pesticides application. As a safe behavior, 196(93\%) farmers have adopted washing hands after pesticide application. And, 82(39\%) farmers store the leftover pesticidesand odds ratio is 0.86 
The odds of farmers not using mask/mouth cover is 0.86 times higher than that of the odds of farmers using mask/mouth cover. Above table shows that many $117(56 \%)$ farmers who do not use mask/mouth cover had headache. Besides, few 12(6\%) farmers using mask/mouth cover also had headache. Hence, there is no significant association between use of mask/mouth cover and headache.

\begin{tabular}{|c|c|c|c|}
\hline \multirow{2}{*}{ Table 1: Socio demographic of respondents } \\
\cline { 2 - 4 } Variables & & Frequency & Percentage \\
\cline { 2 - 4 } & & & \\
\hline Gender & Male & 148 & $70 \%$ \\
& Female & 62 & $30 \%$ \\
\hline Family & Nuclear & 136 & $65 \%$ \\
& Joint & 63 & $30 \%$ \\
& Extended & 11 & $5 \%$ \\
\hline Education & couldn't read & 186 & $87 \%$ \\
& and write & & \\
& could read & 24 & $13 \%$ \\
& and write & & \\
& & & $3 \%$ \\
\hline \multirow{2}{*}{ Age } & Less than 15 & 7 & $24 \%$ \\
& $15-29$ & 50 & $52 \%$ \\
& $30-59$ & 110 & $21 \%$ \\
\hline Farming as & $60+$ & 43 & $90 \%$ \\
& Primary & 189 & $10 \%$ \\
& business & 21 & \\
& Secondary & & \\
& business & & \\
\hline Monthly \\
income & $5000-10000$ & 89 & \\
& $>10000$ & 121 & \\
\cline { 2 - 4 } & & & \\
\hline
\end{tabular}

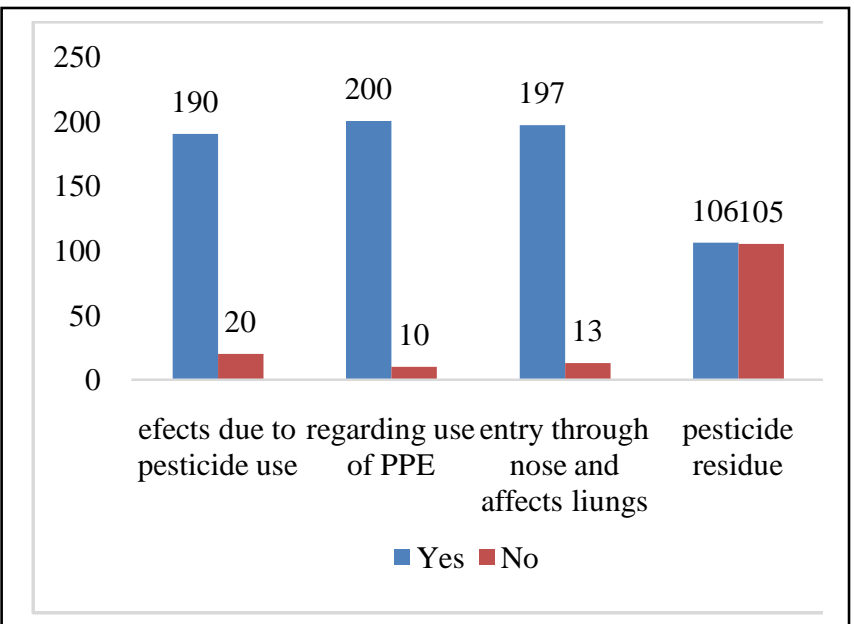

Figure1: Distribution of farmers in relation to knowledge associated with pesticides use

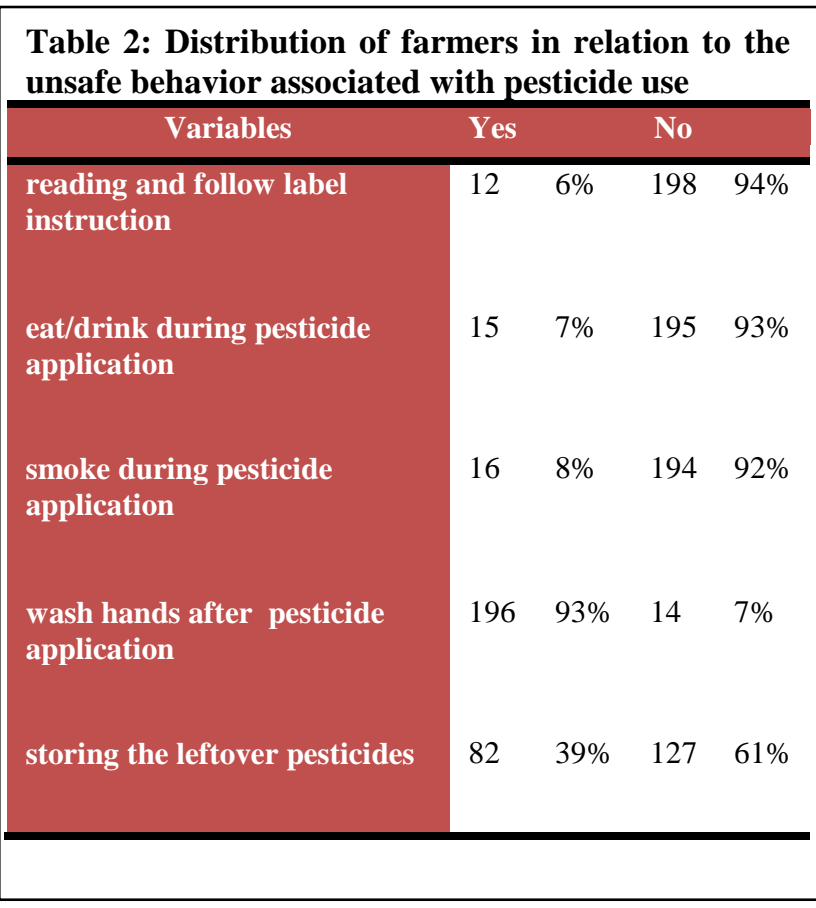

Table 3: Cross tabulation between self-reported immediate health effects and use of PPE

\begin{tabular}{|c|c|c|c|c|c|}
\hline & & \multicolumn{2}{|c|}{ headache } & \multirow[t]{2}{*}{ Total } & \multirow[t]{2}{*}{$\begin{array}{l}\text { p- } \\
\text { value }\end{array}$} \\
\hline & & Yes & no & & \\
\hline \multirow{2}{*}{$\begin{array}{l}\text { Use of } \\
\text { mask/mout } \\
\text { h cover }\end{array}$} & Yes & $\begin{array}{l}61 \\
(29 \%)\end{array}$ & $\begin{array}{l}117 \\
(56 \%)\end{array}$ & $\begin{array}{l}73 \\
(85 \%)\end{array}$ & \multirow{3}{*}{0.87} \\
\hline & no & $\begin{array}{l}12 \\
(6 \%)\end{array}$ & $\begin{array}{l}20 \\
(9 \%)\end{array}$ & $\begin{array}{l}127 \\
(15 \%)\end{array}$ & \\
\hline \multicolumn{2}{|l|}{ Total } & $\begin{array}{l}178 \\
(35 \%)\end{array}$ & $\begin{array}{l}32 \\
(65 \%)\end{array}$ & $\begin{array}{l}210 \\
(100 \%)\end{array}$ & \\
\hline
\end{tabular}

\section{DISCUSSION}

Only farmers using pesticides for agricultural growth was included. Non Probability Purposive sampling technique was used. Structured and semi structured questionnaire were used for collection of data through face to face interview technique. 
The commonest self-reported immediate health effects among farmers in Thimi; Bhaktapur was headache $173(83 \%)$ whereas the commonest symptom among farmers in Gaza strip was Burning sensation in eyes/faces. The prevalence of self-reported toxicity symptoms was dependent on mixing and use of high concentrations of pesticides.

In the present study, the result showed that $(84.7 \%)$ farmers knew the names of pesticides they were using which is consistent to the study conducted byYasin M(2002) which showed 373 (97.9\%) of the participants knew the names of the pesticides they were using.. The most frequent self-reported toxicity symptoms associated with pesticide use among farmers in Thimi was found to be were headache $(35 \%)$, sneezes $(15 \%)$, skin rash $(10 \%)$, and dizziness $(8 \%)$ whereas the most frequent self-reported toxicity symptoms associated with pesticide use among farmers in the Gaza strip were skin rash (37.5\%), headache (37\%), excessive sweating (24.9\%), and diarrhea (21.3\%).

The present study showed that the total sum of the knowledge scores was 1,073; the mean knowledge score was 2.8 (SD: 3.2; range: $[(-6)-(8)]$ The knowledge of the farm workers of West Bank, Palestine was assessed and showed that the total sum of the knowledge scores was 1,073; the mean knowledge score was 2.8 (SD: 3.2; range: $[(-6)-(8)]$. Information regarding pesticide knowledge was mostly obtained from product labels (36\%) and from experience (29.4\%). (Zyoud, 2010)Good knowledge was significantly associated with: secondary education level $(P<0.001)$, college education level $(P=0.01)$ in Palestine whereas there is no significant relationship between education and knowledge about pesticides use $(\mathrm{P}=0.99)$

\section{CONCLUSION}

The most commonly used pesticide is metacid and $16 \%$ farmers could not name pesticides they were using. Most of farmers $(29 \%)$ mentioned they were not using PPE due to carelessness such as staying in rush to the farm to carry PPE along with.

The total sum of the knowledge scores was 545; the mean knowledge score was 2.5 (SD: 3.2). There is no significant association (0.98) between knowledge regarding use of knowledge about the route of exposure and use of mask/mouth cover. Similarly, there is no significant association (0.99) between education and knowledge about route of exposure. There is no significant association (0.42) between knowledge about health effects of pesticides and its storage practices.

\section{COMPETING INTERESTS}

I declare that I don't have competing of interest.

\section{ACKNOWLEDGEMENTS}

I am thankful to Mr. Ram Chandra Sinha, Dr. Shyam Prasad Lohani and Mr. Saroj Bhandari for their constructive feedback and suggestions during study period.

\section{REFERENCES}

1. 1 D Reddy Y, P Kumar P, R Devi B, K Dubey P, B Kumari Y. A Facile and Green synthesis of novel imide and amidic acid derivatives of phenacetin as potential analgesic and anti-pyretic agents. Letters in Organic Chemistry. 2013 Jan $1 ; 10(1): 70-6$

2. Rahman MH, Alam MJ. Risk assessment of pesticides used in Bangladesh. Journal of Civil Engineering. 1997; 25(1):97-106.

3. Risk R. Setting Priorities and Strategies for Environmental Protection. US Environmental Protection Agency, Washington, DC. 1990 Sep. 
4. Indira devi. Economic and political weekly. Pesticides in agriculture- A boon or a curse? A case study of kerala. 2010;14:26-27

5. Khan.M et.al. Assessing farmer's Pesticide Safety Knowledge in cotton growing area of Punjab, Pakistan. 2009. Paper No. 16220

6. Kumari PL, Reddy KG. Knowledge and Practices of safety use of Pesticides among Farm workers. IOSR J. Agric. Vet. Sci. 2013; 6(2):1-8.

7. Lorenz AN. Assessment of Pesticide Knowledge, Attitudes, and Practices among Pregnant Women in Northern Thailand (Doctoral dissertation, Emory University).

8. Rajasekaran B. A framework for incorporating indigenous knowledge systems into agricultural research and extension organizations for sustainable agricultural development in India.

9. Neupane RR, Wantamutte AS, Banjade B, Kushwaha N, Neupane R. Practice of Pesticides Use Among The Farmers of Kangrali Village In Belgaum-A Cross-sectional Study.2014;, 202-207.

10. Williams DR. Racial/ethnic variations in women's health: the social embeddedness of health. American journal of public health. 2002 Apr; 92(4):588-97.

11. Sa'ed HZ, Sawalha AF, Sweileh WM, Awang R, Al-Khalil SI, Al-Jabi SW, Bsharat NM. Knowledge and practices of pesticide use among farm workers in the West Bank, Palestine: safety implications. Environmental health and preventive medicine. 2010 Jul 1; 15(4):252-61.

\section{Article history}

Received : 20 July, 2015

Accepted : 29 September, 2015

Published online: 15 October, 2015

\section{For citation:}

Sainju R.Farmers Knowledge, Practices and Perceived Health Symptoms Associated with Pesticides used in Thimi, Bhaktapur, Nepal. International Journal of Medicine \& Biomedical sciences. 2015; 1(1):23-27 